\title{
INFRAESTRUTURA NA AMAZÔNIA: as lições dos planos plurianuais ${ }^{1}$
}

\author{
Philip Martin Fearnside* \\ William Frederick Laurance ${ }^{* *}$
}

\begin{abstract}
O sistema de avaliação de impacto ambiental no Brasil ainda não é capaz de lidar com o desafio apresentado pelos planos plurianuais, que têm sido a forma de organizar as prioridades do governo desde 1996. Espera-se que esse desafio resulte no fortalecimento do sistema. Problemas genéricos com o processo de licenciamento incluem: a formação de lobby a favor da construção, antes de serem tomadas as decisões sobre a prudência dos projetos; o "efeito arrasto" de terceiros, devido à atividade econômica estimulada pela infraestrutura, que escapa do sistema de avaliação de impacto ambiental; uma forte tendência para empresas de consultoria produzirem relatórios favoráveis, como resultado de tentações embutidas no sistema; uma ênfase burocrática na existência de passos, tais como a submissão de relatórios e a realização de audiências públicas, sem considerar o conteúdo do que é dito; e a inabilidade do sistema de avaliação de impactos de considerar a cadeia de eventos que são deslanchados quando um determinado projeto é empreendido. O exemplo dos planos plurianuais, desde o Brasil em Ação (1996-1999) até o atual PAC2 (Programa de Aceleração do Crescimento-2, 2012-2015), deixa clara a necessidade de se repensar a maneira como grandes programas de desenvolvimento são decididos e promovidos, assim como a necessidade de se reconsiderar a prudência de vários projetos que os compõem.

PALAVRAS-chave: Amazônia, desmatamento, impacto ambiental, rodovias.
\end{abstract}

\section{PROTEÇÕES AMBIENTAIS E OS PLANOS PLURIANUAIS}

Os Planos Plurianuais são conjuntos de investimentos do governo federal brasileiro para períodos de quatro anos. Os planos até agora são: Brasil em Ação (1996-1999), Avança Brasil (2000-2003), PPA (Plano Plurianual, 2004-2007), PAC (Programa de Aceleração do Crescimento, 2008-2011), e PAC-2 (2012-2015). O aspecto mais marcante dessa forma de planejamento são as grandes obras na Amazônia, como rodovias e hidrelétricas. Devido à

${ }^{1}$ As pesquisas do primeiro autor são financiadas pelo Conselho Nacional do Desenvolvimento Científico e Tecnológico (CNPq: Proc. 305880/2007-1; 304020/2010-9; 573810/20087; 575853/2008-5) e o Instituto Nacional de Pesquisas da Amazônia (INPA:PRJ13.03). Agradecemos ao Paulo Maurício Lima de Alencastro Graça pelos comentários.

* Doutor em Ciências Biológicas pela University of Michigan - Ann Arbor. Pesquisador titular III do Instituto Nacional de Pesquisas da Amazônia (INPA) e Bolsista de Produtividade em Pesquisa do CNPq. Nivel 1A C.P. 2223. Cep: 69011-970. Manaus - Amazonas - Brasil. pmfearn@inpa.gov.br

** Doutor em Zoologia da Universidade de Califórnia, Berkeley. Ilustre Professor de Pesquisa e Laureado Australiano na Universidade James Cook, Austrália, e Cadeira Príncipe Bernhard em Conservação Internaciona da Natureza na Universidade de Utrecht, Países Baixos. bill.laurance@jcu.edu.au falta de recursos para executar todas as obras no ritmo acelerado proposto nos planos, é frequente que as mesmas obras sejam propostas em uma sequência de planos. Mesmo assim, os planos têm um grande efeito em acelerar o licenciamento ambiental, a licitação e o financiamento das grandes obras de infraestrutura.

Os proponentes dos planos plurianuais enfatizam a existência de agências ambientais federais e estaduais, polícia, etc., dando a impressão de que o processo de ocupação da terra e desmatamento, na Amazônia, é ordenado e controlado (e.g., Brasil. Ministério do Planejamento, 2002; Silveira, 2001), o que não corresponde à realidade, já que, muito frequentemente, essa atividade acontece ilegalmente (e.g., Carvalho et al., 2002; Laurance et al., 2001a). Fazer cumprir os regulamentos que existem no papel é um problema grave na fronteira. Um relatório da Secretaria de Assuntos Estratégicos (SAE) indicou que $80 \%$ da exploração madeireira na região é ilegal (Cotton; Romine, 1999). Atividades ilegais de desmatamento, garimpagem e caça também são comuns.

A inclusão de projetos não destrutivos nos 
planos plurianuais, como o programa PROBEM para bioprospecção, não muda o efeito dos componentes de infraestrutura. Essa infraestrutura é volumosa, incluindo aumentos significativos no impacto da rede de estradas. No caso do Avança Brasil, a reivindicação dos proponentes de que o plano não contivesse "nenhuma rodovia nova" dava a impressão enganosa de que a rede de rodovias asfaltadas pelo plano não causaria desmatamento. Infelizmente, o plano para pavimentar $7.500 \mathrm{~km}$ de rodovias aumentaria a acessibilidade de áreas remotas da Amazônia para fazendeiros, madeireiros e outros. As rodovias BR-163 e BR-319 são especialmente danosas porque elas cortam blocos grandes de floresta relativamente intacta (Fearnside, 2002, 2007; Fearnside; Graça, 2009).

É importante entender que a exigência de estudos de impactos ambientais (Quadro 1) não garante que projetos prejudiciais não sejam reali- zados. É altamente improvável o resultado sugerido pelo diretor de Avança Brasil, José Paulo Silveira (2001): ele afirmou que a pavimentação de estradas e outros projetos causariam impactos mínimos, devido às exigências atuais no Brasil de avaliações de impacto ambiental, à capacidade do País para monitorar por satélite o desmatamento, e à lei de crimes ambientais (Lei federal 9.605 de 12 de fevereiro de 1998). As subidas e descidas da taxa de desmatamento nem sempre são explicadas com base nesses instrumentos. Por exemplo, em 1995, a taxa de desmatamento saltou para $29.059 \mathrm{~km}^{2} /$ ano, ou o dobro da taxa anual nos anos anteriores (INPE, 2012), apesar de o sistema atual de regulação estar vigente, com exceção da lei de crimes ambientais. Também é importante perceber a distinção entre o que é requerido legalmente e o que acontece na prática. Enquanto as práticas atuais de licenciamento representam muitas vitórias duramente conquistadas na melhoria gradual

Quadro 1 - O sistema de licenciamento ambiental no Brasil(a)

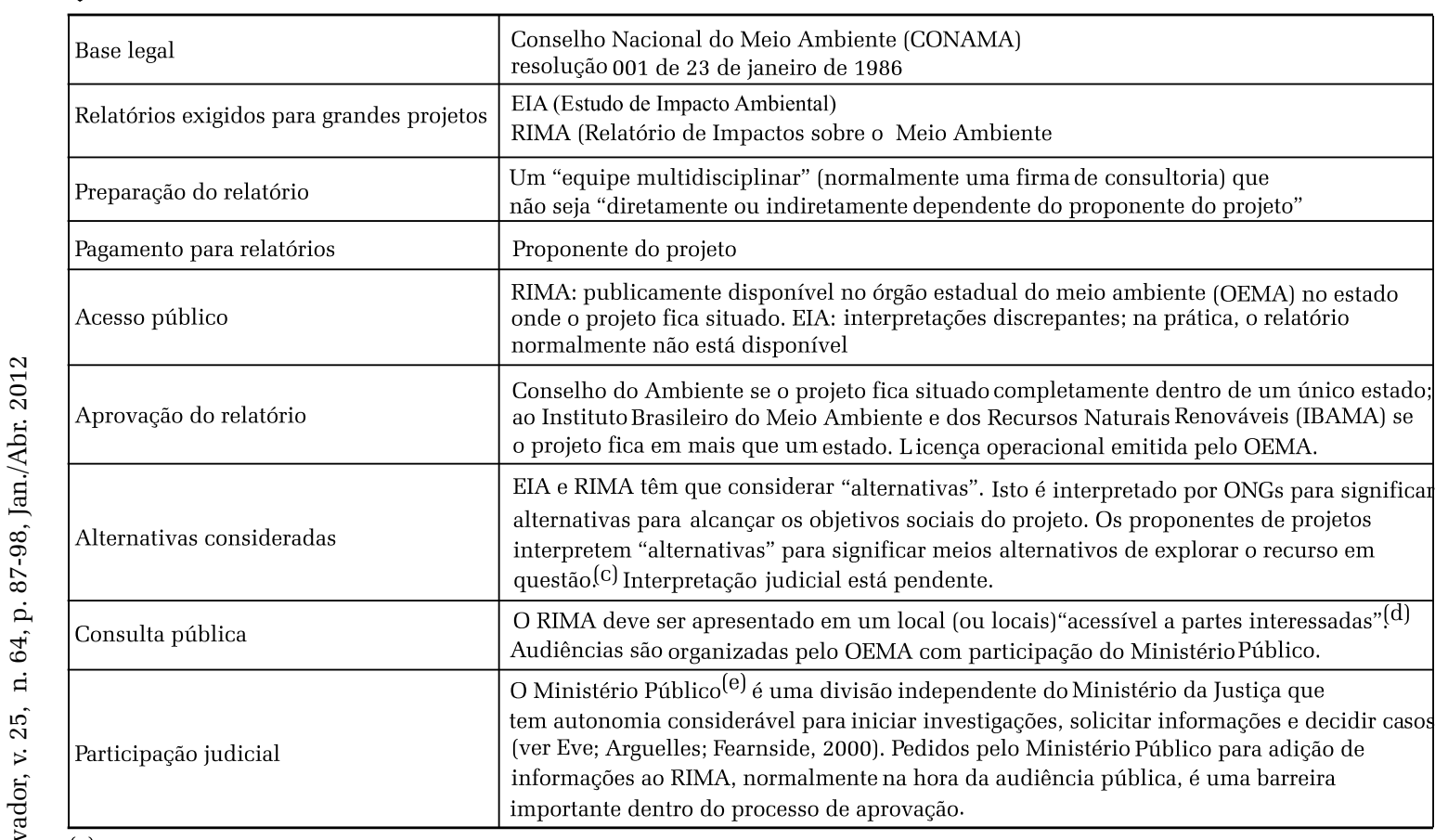

(a) Adaptado de Fearnside (2002).

(b) O "Conselho do Ambiente" em cada estado é designado pelo governo de estado. Estes conselhos são dominados frequentemente por interesses empresariais locais que são favoráveis a projetos de infraestrutura (ver Carvalho et al., 2002).

c) Por exemplo, alternativas ao gasoduto Urucu-Porto Velho são interpretadas por ONGs para incluir outras formas de provisão de eletricidade para Rondônia (usinas hidrelétricas, linhas de transmissão, outras fontes de gás, etc.), mas o proponente do gasoduto alegou que alternativas são restritas aos meios de transportar o gás de Urucu (i.e., gasodutos versus barcaças).

(d) CONAMA resolução 009 de 03 de dezembro de1987.

(e) Autorizado através da Lei No. 7.347 de 24 de julho de 1985 (Lei dos Interesses Difusos) e pela Constituição Brasileira de 1988. 
do sistema, é incorreto supor que o resultado elimina as preocupações sobre impactos ambientais causados pela infraestrutura projetada. Quando são examinados exemplos específicos dos estudos e de relatórios de impacto (EIA/RIMA), é evidente a inabilidade do sistema para traduzir os impactos ambientais e as preocupações das populações afetadas em fatores considerados na tomada de decisão (e.g., Eve; Arguelles; Fearnside, 2000; Fearnside; Barbosa, 1996a; Santos; Hernandez, 2009).

\section{PROBLEMAS GENÉRICOS COM O PROCES- SO DE LICENCIAMENTO}

\section{Lobby estimulado antes da decisão}

Um problema constatado é que poderosos grupos de interesse, a favor de construção de cada projeto, são mobilizados antes de os impactos ambientais e sociais serem avaliados. Essa avaliação somente acontece pouco antes do começo da construção. Cada plano plurianual lança uma página na web em língua inglesa para atrair financiamentos internacionais, antecedendo-se, obviamente, aos estudos ambientais de cada projeto. Oficiais brasileiros de alto nível fazem viagens internacionais para explicar o programa a potenciais investidores. São apresentados os projetos como se fossem um restaurante de comida a quilo, no qual os investidores em potencial podem escolher os investimentos que lhes interessam. Isso acontece antes de o País pesar os custos e benefícios dos projetos propostos, especialmente os impactos ambientais e sociais. Uma vez que o financiamento é mobilizado para um projeto, um lobby com interesses financeiros na aprovação do projeto se forma automaticamente, aumentando, assim, a probabilidade de aprovação governamental, independentemente dos impactos ambientais e sociais que possam ser provocados.

\section{ÊNFASE NA EXISTÊNCIA DE PASSOS}

Um problema geral do sistema de licenciamento é o fato de se requerer apenas que cada passo do processo seja completado (entrega de relatório, audiência pública, etc.), com pouca consideração, na prática, para o conteúdo das informações. Com efeito, os consultores que escrevem os relatórios e os testemunhos nas audiências públicas podem dizer qualquer coisa, até mesmo mostrar impactos graves, o que não impede o prosseguimento do processo de aprovação do projeto, com base no fato de que os relatórios foram devidamente submetidos e a população foi “consultada” (Eve; Arguelles; Fearnside, 2000; Fearnside; Barbosa, 1996a).

\section{O “EFEITO ARRASTO” DE TERCEIROS}

A existência de estudos de impacto ambiental não impede que projetos prejudiciais sejam empreendidos. A afirmação de que qualquer projeto que envolve dano ambiental deve ser reformulado ou abandonado (e.g., Brazilian Embassy London, 2001) não coincide com a experiência. Um dos problemas é que o Estudo de Impacto Ambiental (EIA) e o Relatório de Impactos sobre o Meio Ambiente (RIMA) somente se reportam a impactos diretos, tais como o de colocar o leito de uma rodovia. Os principais impactos dos projetos de infraestrutura, que são os danos indiretos causados pelas atividades econômicas atraídas e facilitadas pelos projetos, escapam completamente do EIA, do RIMA e do processo decisório. Os impactos das atividades de terceiros - fazendeiros e madeireiros -, que se acentuam quando as áreas se tornam de fácil acesso, não estão incluídos nesses relatórios. Ironicamente, as descrições dos benefícios dos projetos frequentemente exaltam os lucros econômicos das atividades, o que os planejadores chamam de "efeito arrasto", mas o mesmo não se aplica aos impactos das atividades (Fearnside, 2001a). No caso da hidrovia do rio Madeira, José 
Paulo Silveira (declaração pública, 1998), então diretor do plano plurianual Brasil em Ação, calculou que o "efeito arrasto" iria atrair US\$3 em atividades econômicas adicionais para cada dólar investido na hidrovia. A hidrovia, em si, é um efeito colateral dos planos para barragens do rio Madeira, começando com as hidrelétricas de Santo Antônio e Jirau, hoje em construção. O plano para hidrovias na bacia do rio Madeira apresenta estimativas de benefícios econômicas enormes, inclusive em 4 mil km de rios na Bolívia (PCE; FURNAS; CNO, 2002). No entanto, os estudos ambientais para as hidrelétricas não incluíram menção alguma ao impacto associado aos efeitos colaterais dessas obras (FURNAS; CNO; LEME ENGENHARIA, 2005).

A rodovia BR-163 (Santarém-Cuiabá) fornece um exemplo dramático do "efeito arrasto". Essa rodovia abre acesso a vastas áreas de floresta relativamente intacta, particularmente suscetíveis à degradação por fogo, devido à forte estação seca na área (Carvalho et al., 2001; Nepstad et al., 2000, 2001). Pavimentar a BR-163 é uma prioridade desde o início dos planos plurianuais, mas trata-se de uma ação que vem sendo adiada devido à falta de recursos. A finalidade principal da rodovia é o transporte de soja do norte de Mato Grosso para o porto de Santarém e se previa que grande parte do custo da obra seria coberta pela agroindústria (Fearnside, 2007). No entanto, em 2003, o preço internacional da soja despencou subitamente, e, desde 2002, o câmbio do dólar norte-americano piorou muito do ponto de vista dos exportadores de soja, caindo de quase R $\$ 4 / \mathrm{US} \$$ para menos de R $\$ 2 / \mathrm{US} \$$. O preço estimado da obra também duplicou em 2003. Portanto, a vontade de a indústria financiar a obra diminuiu, fazendo com que dependesse do orçamento federal. Ao longo dos 15 anos em que a rodovia vem sendo planejada, houve uma migração de serrarias para a área (e.g., Schneider et al., 2000, p.19), e essa área se tornou um dos principais focos de desmatamento na Amazônia (INPE, 2009, p.7).

Os proponentes do Avança Brasil frequen- temente sugerem que a infraestrutura do programa, na região amazônica, terá impactos ambientais mínimos, porque empregará "tecnologia ambientalmente amigável”, com exigências federais e estaduais de relatórios sobre a avaliação de impactos ambientais. E ainda porque os programas plurianuais incluem uma seleção de "projetos ambientais" além da construção de infraestrutura (e.g., Brazilian Embassy London, 2001). Infelizmente, nada disso altera a natureza básica dos programas plurianuais e os cenários para o futuro da Amazônia, tal comoo foram apresentados por Nepstad et al. (2000) e Laurance et al. (2001b).

\section{TENDÊNCIA PARA RELATÓRIOS FAVORÁVEIS}

Empresas consultoras tendem a preparar relatórios favoráveis à aprovação dos projetos, já que as consultorias são contratadas pelos proponentes dos projetos em foco, que têm interesses financeiros pesados na sua aprovação (e.g., Fearnside; Barbosa, 1996b). O Estudo de Impacto Ambiental (EIA) e o Relatório de Impactos sobre o Meio Ambiente (RIMA) são custeados pelo proponente do projeto, o qual, assim, tem influência na escolha do pessoal que é contratado, na fixação de prazos finais quase impossíveis, dando atenção sumária aos problemas causados pelos projetos. Acrescente-se que o proponente revisa uma série de rascunhos preliminares dos relatórios (com oportunidades para "sugerir" supressões e outras mudanças) antes de os relatórios finais serem submetidos às autoridades governamentais. Frequentemente, os contratos estipulam que o pagamento da última prestação dos honorários da empresa consultora só será feito depois que as autoridades ambientais do governo aprovarem o relatório. Dessa forma, é praticamente garantindo que o relatório será elaborado enfatizando os aspectos positivos do projeto proposto.

A hidrovia Araguaia-Tocantins fornece um exemplo. Nesse caso, quando foram incluídas, no relatório, declarações que consideravam pe- 
sados os impactos sobre populações indígenas ao longo da rota, o resultado foi o de alterar o relatório, ao invés de sustar o projeto (Carvalho, 1999; Switkes, 1999). A hidrovia foi embargada temporariamente por ordem judicial (Silveira, 1999), mas a empresa, posteriormente, conseguiu uma liminar permitindo a continuação.

A hidrovia Teles Pires-Tapajós também foi assunto de um escândalo que envolve seus estudos de impacto ambiental. Nesse caso, o projeto foi dividido em dois estudos, um para o trecho acima e outro para o trecho abaixo da área indígena, Mundurucu, que é cortada pela hidrovia (Novaes, 1998). O projeto foi barrado, desde 1997, por uma ordem judicial, mas continuava aparecendo no "restaurante de comida a quilo", como investimento em potencial apresentado a possíveis investidores (e.g., Consórcio Brasiliana, 2000). O projeto figura no PAC-2 como o novo eixo de integração da hidrovia JuruenaTapajós. A hidrovia teria de ter a hidrelétrica de Chacorão, para transpor a cachoeira do mesmo nome no rio Tapajós (e.g. Brasil. Ministério dos Transportes, 2010). Curiosamente, essa barragem, que inundaria 18.721 hectares da área indígena Mundurucu, não consta no Plano de Expansão Energética (PEE) 2011-2020, nem na versão atual do PAC-2 (Brasil. MME, 2011; Brasil. Presidência da República, Casa Civil, 2011, p.74). A possibilidade existe, portanto, de ser deslanchada uma cadeia de eventos a partir das demais barragens no Tapajós, já em acelerada fase de preparação para licenciamento. O caso mais conhecido desse tipo de problema, no entanto, é o do rio Xingu acima da hidrelétrica de Belo Monte.

\section{DESLANCHAMENTODE CADEIASDEEVENTOS}

\section{O exemplo de Belo Monte}

Um dos problemas inerentes ao atual sistema de avaliação de impacto ambiental no Brasil é que apenas um projeto proposto é considerado de cada vez, sem levar em conta os ou- tros projetos que podem ser iniciados em consequência da implementação do primeiro. Exemplos clássicos são os das hidrelétricas de Belo Monte e Altamira (Babaquara) (ver Fearnside, 1989, 1996, 1999a). Essas represas planejadas são o foco de uma das grandes controvérsias ambientais na Amazônia, hoje.

Os impactos de represas hidrelétricas são severos em muitas formas, e vão além de transformações de uso da terra (WCD, 2000). Pouca evidência existe de que aconteceu alguma mudança fundamental na seleção de projetos no Brasil. A hidrelétrica planejada de Belo Monte (que era conhecida como "Kararaô" antes de 1992), alta prioridade desde o plano Avança Brasil, está estreitamente ligada ao projeto muito mais prejudicial de Altamira (Babaquara), que regularia o fluxo do rio Xingu para compensar o reservatório pequeno na hidrelétrica de Belo Monte (Santos; Andrade, 1990; Fearnside, 2001b, 2006).

Em 1989, uma mulher indígena ameaçou com um facão Antônio Muniz, diretor da ELETRONORTE, empresa estatal elétrica na Amazônia, como parte de um protesto contra as seis represas que foram planejadas na época, na Bacia do Xingu-Iriri, especialmente a hidrelétrica de Babaquara. Nos anos seguintes, as autoridades governamentais declararam, muitas vezes, que Babaquara não seria construída, mas ela reapareceu com um nome novo (hidrelétrica de Altamira) no plano para expansão hidrelétrica no país, com data marcada, na época, para conclusão em 2013. Isso se refere à hidrelétrica de Altamira, de $6.140 \mathrm{~km}^{2}$, antigamente chamada de "Babaquara" (ELETROBRÁS, 1998, p.148).

O reaparecimento de planos para a hidrelétrica de Babaquara foi o indicativo de um problema básico: a falta de um mecanismo legal através do qual o governo possa se comprometer a não executar projetos específicos que são identificados como danosos. Quando projetos são julgados como politicamente pouco promissores, devido a críticas a seus impactos esperados, eles podem simplesmente ficar latentes durante décadas, para depois reemergirem em um mo- 
mento mais politicamente favorável. Tais obras são conhecidas como "projetos vampiros".

No caso da barragem Atlamira ou Babaquara, a obra foi retirada dos planos oficiais para o rio Xingu em julho de 2008, através de uma decisão do Conselho Nacional de Política Energética (CNPE). No entanto, há indícios fortes de que continua em planos não oficiais. Por exemplo, o diretor-presidente da Agência Nacional de Energia Elétrica (ANEEL) deixou claro que considerava a decisão um posicionamento político irracional (Pamplona, 2008), e a Dilma Rousseff, então encarregada da Casa Civil, vetou a proposta para uma reserva extrativista elaborada pela então Ministra do Meio Ambiente Marina Silva, com base no argumento de que "poderia atrapalhar a construção de barragens adicionais à usina de Belo Monte" (Ângelo, 2010). Nada impede que a CNPE simplesmente mude a sua decisão sobre o rio Xingu no futuro. Mudanças análogas de promessas de autoridades da área elétrica têm sido o padrão histórico em outras barragens, como Balbina e Tucuruí-II (Fearnside, 2006). A grande oscilação sazonal da vazão do rio Xingu faz com que os 11 mil MW de capacidade instalada nas turbinas da casa de força principal fiquem ociosos durante quatro meses do ano, caso não haja outras barragens para armazenar água rio acima. Esse fato levanta dúvidas sobre a durabilidade do cenário oficial de apenas uma barragem (Belo Monte) no rio Xingu (Fearnside, 2011a; Sousa Júnior; Reid; Leitão, 2006). Esse cenário, de uma única barragem no rio Xingu, ficou conhecido como a "mentira institucionalizada" por oponentes a Belo Monte (e.g., Nader, 2008). A dimensão do impacto ambiental e humano da decisão sobre a construção de Belo Monte é crítica, pois as barragens acima de Belo Monte inundariam vastas áreas de terras indígenas, quase todas em floresta tropical. As barragens rio acima também têm um grande potencial de gerar emissão de gases de efeito estufa (Fearnside, 2009, 2011b). Nada desse impacto foi considerado no EIA/RIMA de Belo Monte, que presume haver apenas essa barragem no rio Xingu.

\section{O exemplo da hidrovia Araguaia-Tocantins}

Eclusas na barragem Luis Magalhães (Lajeado) fornecem outro exemplo do perigo de um processo de aprovação a retalhos. A construção das eclusas não teria propósito, a não ser que se torne o resto do rio Tocantins navegável, levando a cabo a hidrovia Araguaia-Tocantins como um todo. Os proponentes das eclusas travaram uma batalha legal para permitir o começo da construção, com aprovação pelo Estado de Tocantins como um projeto isolado, antes que a hidrovia fosse decidida como um todo. No final, as eclusas de Lageado foram autorizadas sem a análise e a aprovação do projeto maior da hidrovia.

\section{CUSTOS DE OPORTUNIDADE DE PERDA DE FLORESTA}

O desmatamento conduz, inevitavelmente, à perda de oportunidade para uso sustentável de floresta em pé, inclusive o aproveitamento do valor de serviços ambientais (Fearnside, 1997). Serviços ambientais incluem a manutenção de biodiversidade (Fearnside, 1999b), ciclagem de água (Silva Dias et al., 2002; Laurance et al., 2002; Fearnside, 2004) e controle da emissão de gases do efeito estufa. O armazenamento de carbono é o serviço ambiental que está mais próximo de render lucros monetários significativos.

No contexto brasileiro, se só for permitido o uso das taxas de desmatamento históricas como a linha de base, a partir de qual o crédito de carbono será concedido -, então a maneira de agir seria de "cercar" (figurativamente) remanescentes de florestas, em partes do Brasil que já tenham passado por um pesado desmatamento histórico, e, por outro lado, não haveria nenhum crédito para evitar a abertura futura de áreas atualmente intactas. O exemplo dos planos plurianuais ilustra porque vale a pena encontrar maneiras de fazer com que o crédito para evitar o desmatamento se aplique também às novas fronteiras. $\mathrm{O}$ que torna os planos plurianuais tão danosos ao meio 
ambiente, inclusive o seu papel como fonte de emissões de carbono, é que se abrem vastas áreas "virgens" para desmatamento, exploração madeireira e incêndios florestais. O preço provável de não criar regulamentos que dão crédito, por evitar esses impactos, seria transformar em realidade os cenários gerados em computador. Claramente, as apostas são altas.

\section{BENEFÍCIOS DE INFRAESTRUTURA DE EXPORTAÇÃO}

Uma pergunta básica a ser respondida com respeito à infraestrutura de exportação, para qualquer projeto planejado, é se os benefícios compensam o custo. Infelizmente, os benefícios de infraestrutura de exportação são escassos, especialmente em termos de benefícios sociais para o Brasil. O investimento público na infraestrutura, como também o investimento privado nas atividades servidas pelas obras, representa um tremendo custo de oportunidade, já que muitos outros tipos de desenvolvimento resultariam em maiores benefícios locais a partir dos recursos financeiros limitados. Por exemplo, a rodovia BR163, que será pavimentada para benefício de exportadores de soja em Mato Grosso, contrasta com a rodovia BR-230 (Transamazônica), no trecho de Marabá para Itaituba, que serve como área já ocupada por pequenos agricultores.

O beneficiamento de alumínio, que é uma das principais atividades a serem supridas pela construção de hidrelétricas planejadas, fornece outro exemplo extremo. A ALBRÁS, que usa energia da rede de transmissão suprida por Tucuruí e outras represas, consome mais eletricidade que a cidade de Belém, mas emprega somente 1.200 pessoas (ver Fearnside, 1999a). Em 2000, 33\% da ALBRÁS foram comprados por companhias norueguesas, e o plano para dobrar a capacidade de produção foi anunciado.

A hidrelétrica de Serra Quebrada, a ser construída no rio Tocantins por companhias de alumínio internacionais (Alcoa e Billiton), foi parte do plano Avança Brasil e planos sucessores para transformar esse rio em uma escadaria de represas. Nesse caso, o reservatório deslocaria um número grande de pessoas (aproximadamente 15.000) e inundaria parte de duas reservas indígenas, assim como afetaria também florestas inundadas (Themag, 2000).

Se a energia é para ser usada para o alumínio, então não há praticamente limite algum à quantidade de capacidade geradora "necessária”. O Brasil seria sábio se estabelecesse primeiro as suas políticas sobre e para que a eletricidade será usada, antes de decidir sobre projetos de construção de novas hidrelétricas. Um critério primário para avaliar usos de energia deveria ser o número de empregos criados por unidade de eletricidade consumida. No caso do alumínio para exportação, as duas usinas de alumínio providas pela hidrelétrica de Tucuruí consomem, anualmente, $6 \mathrm{MWh}$ de energia para cada um dos 1.950 postos de trabalho criados como emprego direto. Considerando só o custo proporcional de construir a hidrelétrica de Tucuruí, esses empregos valeram US\$ 2,7 milhões cada (Fearnside, 1999a). Se decisões sobre projetos hidrelétricos estiverem baseadas em benefícios sociais no Brasil, seria improvável que a decisão fosse de fornecer energia para a produção de alumínio para exportação.

A noção de que projetos como rodovias e hidrovias melhorarão a situação dos amazônidas pobres é pouco realista. Esses projetos são elaborados, principalmente, para transportar mercadorias como a soja. São de interesse de empresas agroindustriais intensivas de capital, e geram muito poucos empregos (Fearnside, 2001a). Por exemplo, no Maranhão, uma média de 167 ha de soja é necessária para criar um emprego, de acordo com um levantamento feito pela Empresa Brasileira de Pesquisa Agropecuária - EMBRAPA (Carvalho, 1999). A soja está sendo frequentemente produzida em cerrados, e é transportada por rodovias, hidrovias e estradas de ferro que passam pelas áreas de floresta. Nas próprias áreas de floresta, a pecuária bovina é o 
principal uso de terra e rapidamente domina a paisagem em áreas que foram abertas ao transporte. A pecuária beneficia uma elite rica e fornece uma quantidade mínima de emprego (Fearnside, 2001c). No caso de exploração madeireira, o emprego gerado provavelmente será temporário, porque a maior parte da exploração madeireira na Amazônia é insustentável (Cotton; Romine, 1999). Uma vez que muito da infraestrutura está justificada pela exportação de soja, uma cultura com benefícios sociais mínimos, é difícil imaginar a construção de uma rede de infraestrutura volumosa para apoiar a produção de soja sob a rubrica de "desenvolvimento sustentável".

\section{MELHORIA DO SISTEMA DE LICENCIAMENTO AMBIENTAL}

Os planos plurianuais oferecem lições múltiplas para a melhoria do sistema de licenciamento ambiental no Brasil. Fortalecer o sistema requer não só que os relatórios sejam imparciais e completos, mas também que eles entrem no processo de tomada de decisões, antes que sejam definidas as prioridades de infraestrutura. Os planos elevam uma lista de projetos de construção à condição de prioridades nacionais antes de serem identificados os impactos potenciais, e antes que os planos sejam discutidos pela sociedade (ou até mesmo por ministérios que não seja o Ministério do Planejamento). O papel do licenciamento ambiental é inerentemente pequeno quando feito como uma mera formalidade, logo antes do começo da construção em si, ou seja, depois que já foram anunciados os projetos, levantadas as verbas, licitadas as obras e assinados os contratos de construção.

Os estudos poderiam ser melhorados de várias maneiras. Ampliar os estudos para incluir o "efeito arrasto" da atividade econômica estimulada pela infraestrutura é essencial. É impressionante que nenhuma estimativa do desmatamento da infraestrutura proposta foi gerada, nem como uma parte do processo de planejamento dos pla- nos plurianuais, nem como parte do processo de avaliação de impacto ambiental para os projetos individuais. Os estudos disponíveis (Nepstad et al., 2000; Laurance et al., 2001b; Fearnside; Laurance, 2002; Soares-Filho et al., 2006) foram produzidos independentemente desses processos, e os planos já estavam em andamento.

Precisa-se de estudos que avaliem o impacto de conjuntos de projetos relacionados, como no caso de planos de desenvolvimento de bacias hidrográficas, antes de aprovar os projetos individuais. As hidrelétricas do rio Xingu ilustram o perigo de deslanchar cadeias de eventos que são muito mais prejudiciais que os projetos iniciais. Para cada projeto, uma gama completa de alternativas precisa ser analisada, e as alternativas devem ser interpretadas no sentido amplo, para incluir outras formas de alcançar os objetivos sociais dos projetos.

Garantir a objetividade de estudos de impacto requererá enfrentar um arranjo pelo qual o proponente dos projetos pague os estudos ambientais, o que é especificado nos regulamentos que governam o sistema (CONAMA resolução 001 de 23 de janeiro de 1986). Substituir isso com verbas públicas não seria viável, já que elas não estariam disponíveis, na prática, em quantias adequadas e com a velocidade e a eficiência suficientes para fazer o sistema funcionar. Uma solução melhor seria exigir dos proponentes a contribuição de recursos financeiros para um fundo, que seria administrado independentemente, com supervisão do governo. O fundo contrataria os estudos sem envolvimento do proponente. Isso removeria os vieses inerentes no direito atual de o proponente selecionar uma empresa de consultoria, e a influência subsequente desfrutada pelos proponentes sobre as contratações dentro da empresa, o estabelecimento de prazos finais impossíveis e outras limitações que evitam uma avaliação adequada dos impactos, e a revisão de esboços do relatório pelo proponente antes de ele ser entregue às autoridades.

A importância do reforço do sistema de 
licenciamento ambiental se encontra em um momento extremamente delicado e pouco propício. Há uma constante pressão da Presidência da República sobre o Ministério do Meio Ambiente para encurtar o processo de licenciamento das obras dos Planos Plurianuais, diminuindo as exigências ambientais e sociais. Ao mesmo tempo, as duas casas do legislativo são fortemente dominadas por interesses a favor da diminuição das proteções ambientais em geral, o que é demonstrado pelas votações sobre o Código Florestal. Portanto, qualquer legislação proposta para fortalecer o sistema de licenciamento seria, provavelmente, modificada para fazer exatamente o oposto, abrindo, assim, uma brecha o para desfazer as proteções existentes. Portanto, uma fortificação mais profunda do sistema teria de esperar uma mudança mais demorada da evolução do quadro político envolvente.

No entanto, há ajustes menores, possíveis em curto prazo. Por exemplo, a participação pública poderia ser aumentada através de melhores escolhas de local e horário das audiências, e com esforços para facilitar a disponibilidade de documentação pertinente sobre o projeto. Isso sempre deveria incluir a disponibilidade pública de uma versão completa do Estudo de Impacto Ambiental (EIA), não apenas Relatório de Impacto sobre o Meio Ambiente (RIMA), que é mais resumido.

Procedimentos judiciais representam uma parte importante do processo de licenciamento. Uma necessidade importante é a criação de um mecanismo pelo qual possam ser feitos compromissos para não serem implementados certos projetos que são identificados como especialmente danosos. Na ausência de um mecanismo desse tipo, graves problemas, identificados em estudos de projetos interligados, tais como planos para desenvolvimento de bacias hidrográficas, teriam pouco efeito em potencial, a não ser a possível negação de autorização da obra inicial em cada conjunto de projetos.

O envolvimento do Ministério Público é uma proteção importante pois assegura a inclu- são de considerações pertinentes nos relatórios e a aderência aos procedimentos que foram especificados para o sistema de licenciamento (ver Tabela 1). Atualmente, esse é o mecanismo principal pelo qual pode ser incluída documentação alternativa no processo de decisão. No entanto, esse tipo de envolvimento judicial não é um substituto para um sistema de licenciamento que funcione por conta própria. Devem ser feitos esforços para fortalecer o sistema de licenciamento, enquanto se mantém a proteção fornecida pelo setor jurídico.

\section{CONCLUSÕES}

O desafio apresentado pelos planos plurianuais deixa clara a necessidade de fortalecer mais o sistema de avaliação de impacto ambiental, que ainda não é capaz de contender com muitos dos tipos de impactos esperados do plano. Eles incluem o "efeito arrasto" de projetos de infraestrutura, em atividades econômicas que conduzem a desmatamento e a outros impactos, como cadeias de jogo de eventos em movimento por projetos interligados como fios de represas hidrelétricas. O cronograma dos passos, no processo de avaliação dos impactos ambientais e no licenciamento das obras, precisa ser mudado para fornecer uma contribuição ao processo de planejamento, em lugar de apenas legitimar projetos depois que já foram tomadas decisões principais. Uma gama completa de alternativas deveria ser avaliada para cada projeto proposto, e uma discussão mais ampla dos objetivos sociais dos projetos precisa ser feita, particularmente nos casos de desenvolvimentos para exportação de soja e alumínio. Várias mudanças poderiam aumentar a independência e a transparência do processo de licenciamento, que atualmente é pesadamente influenciado pelos proponentes dos projetos, que pagam pelos estudos ambientais. Os severos impactos implícitos nos planos plurianuais deixam clara a necessidade de se repensar a maneira como os grandes 
programas de desenvolvimento são decididos e promovidos, assim como a necessidade de se reconsiderar a prudência de implantar vários dos seus projetos componentes.

(Recebido para publicação em 2 de novembro de 2011) (Aprovado em 27 de janeiro de 2012)

\section{REFERÊNCIAS}

ANGELO, C. PT tenta apagar fama 'antiverde' de Dilma. Folha de São Paulo, p. A-15, 10 out. 2010.

BRASIL. Ministério do Planejamento. Avanca Brasil. Brasília, DF: Ministério do Planejamento, 2002. Disponível em: www.abrasil.gov.br/

Ministério dos Transportes. Plano Nacional Hidroviário, 2010. Disponível em: http://www2 transportes.gov.br/Modal/Hidroviario/PNHidroviario.pdf

Ministério de Minas e Energia. Plano decenal de expansão de energia 2020. Brasília, DF: Empresa de Pesquisa Energética, 2011. 2v

Presidência da República. Casa Civil. Geração de energia elétrica, Resultados 2011.PAC-2 - Programa de Aceleração do Crescimento-2, 2011. Disponível em www.brasil.gov.br/pac/relatorios/2011-pac-2/2o-balanco/2obalanco-geracao-de-energia-eletrica/at_download/file

BRAZILIAN EMBASSY LONDON. Plans for the Sustainable Development of the Amazon. London: 2001. 4 p.

CARVAlHO, G.; BARROS, A.C.; MOUTINHO, P.; NEPSTAD, D. Sensitive development could protect Amazonia instead of destroying it. Nature, London, v.409, p.131, 2001.

CARVALHO, G.O.; NEPSTAD, D.; MCGRATH, D.; DIAZ M.C.V.; SANTILLI, M.; BARROS, A.C. Frontier expansion in the Amazon: balancing development and sustainability. Environment, Washington,DC, v.44, n.3, p.34-45, 2002.

CARVALHO, R. A Amazônia rumo ao “ciclo da soja”. Amazônia Papers n.2, São Paulo, Programa Amazônia, Amigos da Terra, 8 f., 1999. Disponível em: http://www.amazonia.org.br.

CONSÓRCIO BRASILIANA. Programa Brasil em ação: eixos nacionais de integração e desenvolvimento. Banco Nacional de Desenvolvimento Econômico e Social (BNDES) PBA/CN-01/97. Relatório Final do Marco Inicial. Brasília, DF. Consórcio Brasiliana, 2000. 3v. does Brazil's environmental law work in practice? Environmental impact assessment and the case of the Itapiranga private sustainable logging plan. Environmental FEARNSIDE, PM. Brazil's Balbina Dam: Environment versus the legacy of the pharaohs in Amazonia. Environmental Management, Washington,DC, v.13, n.4, p.401-423, 1989.

Hydroelectric dams in Brazilian Amazonia: response to Rosa, Schaeffer \& dos Santos. Environmenta
Conservation, Cambridge, Reino Unido, v. 23, n.2, p.105108,1996.

Environmental services as a strategy for sustainable development in rural Amazonia. Ecological Economics, Washington,DC, v.20, n.1, p.53-70, 1997.

Social impacts of Brazil's Tucuruí Dam.


p.485-495, 1999a.

Biodiversity as an environmental service in Brazil's Amazonian forests: Risks, value and conservation. Environmental Conservation, Cambridge, Reino Unido, DC, v.26, n.4, p.305-321, 1999b.

. Soybean cultivation as a threat to the environment in Brazil. Environmental Conservation, Cambridge, Reino Unido, v.28, n.1, p.23-38, 2001a.

Environmental impacts of Brazil's Tucuruí Dam: Unlearned lessons for hydroelectric development in Amazonia. Environmental Management, Washington, DC, v. 27, n.3, p.377-396, $2001 \mathrm{~b}$.

Land-tenure issues as factors in environmental destruction in Brazilian Amazonia: The case of southern Pará. World Development, Philadelphia, Elsevier, v. 29, n.8, p. 1361-1372, 2001c.

Avança Brasil: Environmental and social consequences of Brazil's planned infrastructure in Amazonia. Environmental Management, Washington,DC v.30, n.6, p.748-763, 2002.

. A água de São Paulo e a floresta amazônica. Ciência Hoje, Rio de Janeiro, SBPC, v.34, n.203, p.63-65, 2004

Dams in the Amazon: Belo Monte and Brazil's hydroelectric development of the Xingu River Basin. Environmental Management, Washington,DC, v.38, n.1, p.16-27, 2006.

Brazil's Cuiabá-Santarém (BR-163) Highway: The environmental cost of paving a soybean corridor through the Amazon. Environmental Management, Washington,DC, v.39, n.5, p.601-614, 2007.

As hidrelétricas de Belo Monte e Altamira (Babaquara)

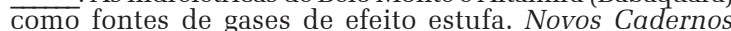
NAEA, Belém, PA, v.12, n. 2, p.5-56, 2009.

Will the Belo Monte Dam's benefits outweigh the costs? Latin America Energy Advisor, Washington,DC, 21 25 Feb. 2011, p.6, 2011a. Disponível em: http:// www.thedialogue.org.

Gases de Efeito Estufa no EIA-RIMA da Hidrelétrica de Belo Monte. Novos Cadernos NAEA, Belém, PA, v.14, n.1, p.5-19, 2011b.

; BARBOSA, R.I. The Cotingo Dam as a test of Brazil's system for evaluating proposed developments in Amazonia. Environmental Management, Washington,DC, v.20, n.5, p. 631-648, 1996a.

Political benefits as barriers to assessment of environmental costs in Brazil's Amazonian development planning: the example of the Jatapu Dam in Roraima. Environmental Management, Washington,DC, v.20, n.5, p. 615-630, 1996b.

GRAÇA, P.M.L.A. BR-319: A rodovia Manaus-Porto Velho e o impacto potencial de conectar o arco de desmatamento à Amazônia central. Novos Cadernos NAEA, Belém, PA, v.12, n.1, p.19-50, 2009.

LAURANCE, W.F. O futuro da Amazônia: os im-

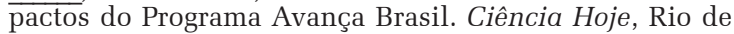
Janeiro, SBPC, v.31, n .182, p.61-65, 2002.

FURNAS (Centrais Elétricas S.A); CNO (Construtora Noberto Odebrecht, S.A.); LEME ENGENHARIA. EIAEstudo de Impacto Ambiental Aproveitamentos Hidrelétri- 
cos Santo Antônio e Jirau, Rio Madeira-RO. 6315-RTG90-001. Rio de Janeiro: 2005. 8v. Disponível em: www.amazonia.org.br/arquivos/195010.zip.

INPE. Instituto Nacional de Pesquisas Espaciais Monitoramento da cobertura florestal da Amazônia por satélites: Avaliação DETER-Agosto de 2009. São José dos Campos,SP: 2009. 11p. Disponível em: www.amazonia. org.br/arquivos/329230.pdf

Projeto PRODES: monitoramento da floresta amazônica brasileira por satélite. São José dos Campos,SP: 2012 Disponível em: www.obt.inpe.br/prodes/.

LAURANCE, W.F; COCHRANE, M.A.; FEARNSIDE, P.M.; BERGEN,S.;DELAMONICA, P.; D'ANGELO, S.; FERNANDES, T.; BARBER, C. Response. Science, Washington, DC, AAAS, v. 292, p.1652-1654, [S.l.] 2001a.

COCHRANE,M.A.; BERGEN, S.; FEARNSIDE, P.M.; DELAMOONICA,P.; BARBER, C.; D'ANGELO, S.; FERNANDES, T. The future of the Brazilian Amazon. Science, Washington, DC, AAAS, v.291, p.438-439, 2001b.

; POWELL, G.; HANSEN, L. A precarious future for Amazonia. Trends in Ecology and Evolution, Philadelphia,USA, Elsevier, v.17, n. 6, p.251, 2002.

NADER, V. Mentira institucionalizada justifica Hidrelétrica de Belo Monte. Correio da Cidadania, São Paulo, 17 jun. 2008. Disponível em: www.correiocidadania.com.br/ content/view/1955/

NEPSTAD, D.; CAPOBIANCO, J.P.; BARROS, A.C. CARVALHO,G.; MOUTINHO, P.; LOPES,U.; LEFEBVRE, P. Avança Brasil: os custos ambientais para Amazônia. Belém, PA: IPAM, 2000. 24 p.

; CARVAlHO, G.; BARROS, A.C.; ALENCAR, A.; CAPOBIANCO, J.P.; BISHOP, J ; MOUTINHO, P. LEFEBVRE, P.; SILVA, U.L Jr.; PRINS, E. Road paving, fire regime feedbacks, and the future of Amazon forests. Forest Ecology and Management, Philadelphia,USA, Elsivier, v.154, n.3, p. 395-407, 2001.

NOVAES, W. Corda em casa de enforcado. O Estado de São Paulo, 07 ago. 1998.

PAMPLONA, N. Aneel chama decisão de limitar usinas no Xingu de 'política'. Agência Estado, 22 jul. 2008. Disponível em: www.estadao.com.br/noticias/economia/aneel-chama-d e c i s a o-d e-limitar-usinas-no-xingudepolitica,209554,0.htm

PCE (Projetos e Consultorias de Engenharia Ltda); FURNAS (Centrais Elétricas S.A.); CNO (Construtora Noberto Odebrecht S.A.). Inventário Hidrelétrico do Rio Madeira: Trecho Porto Velho - Abunã. Processo No 48500.000291/01 31. Relatório Final: MAD-INV-00-01-RT. Rio de Janeiro: 2002. Paginação irregular.

SANTOS, L.A.O.; ANDRADE, L.M.M. de (Org.) Hydroelectric dams on Brazil's Xingu River and indigenous peoples. Cambridge; Massachusetts, E.U.A.: Cultural Survival, 1990. 192 p. (Cultural survival report 30).
SANTOS, S. M.S.B.M.; HERNANDEZ, F.M. (Org.) Painel de especialistas: análise crítica do estudo de impacto ambiental do aproveitamento Hidrelétrico de Belo Monte. Painel de especialistas sobre a Hidrelétrica de Belo Monte, Belém: 2009. 230 p. Disponível em: http:// w w w. in ternat i o n a l r iver s.org/f i l e s/ Belo\%20Monte\%20pareceres\%20IBAMA_online\%20(3).pdf SCHNEIDER, R.R.; ARIMA, E.; VERÍSSIMO, A. BARRETO, P.; SOUZA JUNIOR,C. Amazônia sustentável: limitantes e oportunidades para o desenvolvimento rural. Brasília, DF: World Bank; Belém: Imazon, 2000. 58 p.

SILVA DIAS, M.A.; RUTLEDGE, F.; KABAT, P.; SILVA DIAS,P.L.; NOBRE, C.; FISH, G.; DOLMAN, A.J.; ZIPSER,E.; GARSTANG,M.; MANZI,A.; FUENTES,J.D.; ROCHA,H.; MARENGO, J.; PLANA-FATTORI, A.; SA, L.; ALVALA, R.; ANDREAE, M.O.; ARTAXO, P.; GIELOW,R.; GATTI, L. Cloud and rain processes in a biosphere atmosphere interaction context in the Amazon Region. Journal of Geophysical Research (Atmospheres), Washington, DC, AGU, v.107, n. D20, 8020, doi: 10.1029/ 2001JD000335, 2002.

SILVEIRA, J.P. Development of the Brazilian Amazon. Science, Washington, DC, AAAS, v. 292, p.1651-1652, 2001.

SILVEIRA, W. Juiz suspende licenciamento de hidrovia. Folha de São Paulo, 23 set. 1p.1-7,1999.

SOARES-FILHO, B.S.; NEPSTAD, D.C.; CURRAN, L.M.; CERQUEIRA, G.C.; GARCIA, R.A.; RAMOS, C.A.; VOLL, E.; MCDONALD, A.; MCDONALD, P.; SCHLESINGER, P. Modelling conservation in the Amazon basin. Nature, London, v.440, p.520-523, 2006.

SOUSA JÚNIOR, W.C.; REID, J.; de LEITÃO,N.C.S. Custos e benefícios do Complexo Hidrelétrico Belo Monte: uma abordagem econômico-ambiental. Lagoa Santa,MG Conservation Strategy Fund (CSF),,2006. 90 p. Disponível em: www.conservation-strategy.org

SWITKES, G. Gouging out the heart of a river: Channelization project would destroy Brazilian rivers for cheap soybeans. World Rivers Review, Berkeley, California, E.U.A., IRN, v.14, n. 3, p.6-7, 1999.

THEMAG (Engenharia e Gerenciamento). Aproveitamento hidrelétrico Serra Quebrada: estudo de impacto ambiental: v.4. Diagnóstico do meio sócio-econômico, Tomo $1 / 2-$ texto. Themag No6291-03-GL-830-RT-00048-R0. São Paulo: 2000. Paginação irregular

WORLD COMMISSION ON DAMS - WCD. Dams and development: a new framework for decision-making. London: Earthscan, 2000. 404 p. 


\section{INFRASTRUCTURE IN AMAZONIA: lessons from Brazil's pluri-annual plans}

\author{
Philip M. Fearnside \\ William Frederick Laurance
}

Brazil's environmental impact assessment system is not yet capable of coping with the challenge presented by the pluri-annual plans that have been the means of organizing government priorities since 1996. It is hoped that this challenge results in strengthening of the system. Generic problems with the licensing process include stimulation of a lobby in favor of construction before decisions are made on the advisability of the projects, the "dragging effect" of third parties whereby economic activity is attracted to the infrastructure but escapes the environmental impact assessment system, a tendency for consulting firms to produce favorable reports, a bureaucratic emphasis on the existence of steps such as the submission of reports and the holding of public hearings without regard to the content of what is said, and the inability to take account of the chain of events unleashed when a given project is undertaken. The example of the pluri-annual plans from Brazil in Action (1996-1999) up to the current PAC-2 [Program for the Acceleration of Growth-2] (2012-2015) makes clear the need to rethink how major development decisions are made, and to reconsider a number of the plan's component projects.

KEYWoRDS: Amazonia, deforestation, environmental impact, highways.

\section{INFRASTRUCTURE EN AMAZONIE: les leçons des plans pluriannuels}

\author{
Philip Martin Fearnside \\ William Frederick Laurance
}

Le système d'évaluation de l'impact environnemental au Brésil n'est toujours pas en mesure de relever le défi des plans pluriannuels, élaborés depuis 1996 par le gouvernement, en vue d'organiser ses priorités. Ce défi devrait renforcer le système, c'est ce qu'on en attend. De nombreux problèmes d'ordre général sont liés aux processus d'autorisations, tels que: la formation de lobbying en faveur des constructions, avant même de connaître le bien fondé des projets; le fait "d'entraîner" des tiers, vu les activités économiques engendrées par une infrastructure qui échappe au système d'évaluation de l'impact sur l'environnement; une forte tendance qu'ont les cabinets de consultants d'émettre des rapports favorables, étant donné les tentations inhérentes au système; la lenteur de la bureaucratie pour franchir les étapes, qui exige l'élaboration de rapports et la réalisation d'auditions publiques, sans pour autant tenir compte du contenu de ce qui est dit; et aussi l'incapacité du système en matière d'évaluation des impacts qui doivent être pris en considération dans l'enchainement des événements lorsqu'un projet spécifique est entrepris. L'exemple des plans pluriannuels, allant du "Brésil en Action" (19961999) au plan actuel "PAC-2" (Programme d'Accélération de la Croissance-2, 2012-2015), met en évidence la nécessité de repenser la façon de décider et de promouvoir les programmes de développement majeurs ainsi que le besoin de reconsidérer la raison d'être des projets qui les composent.

Mots-Cles: Amazonie, déforestation, impact environnemental, routes.

\footnotetext{
Philip Martin Fearnside - Doutor em Ciências Biológicas pela University of Michigan - Ann Arbor. Pesquisador titular III do Instituto Nacional de Pesquisas da Amazônia (INPA) e bolsista de produtividade em pesquisa do CNPq. Nivel 1A. Estuda problemas ambientais na Amazônia brasileira desde 1974. Realiza pesquisas ecológicas, incluindo a estimativa de capacidade de suporte de agro-ecossistemas tropicais para populações humanas e estudos sobre impactos e perspectivas de diferentes modos de desenvolvimento na Amazônia e sobre as mudanças ambientais decorrentes do desmatamento da região. Em 2004 foi vencedor do Prêmio da Fundação Conrado Wessel na área de Ciência Aplicada ao Meio Ambiente. Em 2006 recebeu do Ministério do Meio Ambiente o Prêmio Chico Mendes com $1^{\circ}$ lugar na área de Ciência e Tecnologia. Seus trabalhos estão disponíveis através do site http://philip.inpa.gov.br.

William Frederick Laurance - Doutor em Zoologia da Universidade de Califórnia, Berkeley. Ilustre Professor de Pesquisa e Laureado Australiano na Universidade James Cook, Austrália, e Cadeira Príncipe Bernhard em Conservação Internacional da Natureza na Universidade de Utrecht, Países Baixos. Foi Pesquisador visitante no Departamento de Ecologia do Instituto Nacional de Pesquisas da Amazônia. Tem experiência na área de Ecologia com ênfase em Ecologia Aplicada. Atua principalmente na produção cientifica nos seguintes temas: Australia, mamíferos não voadores, Queensland, Amazônia.
} 